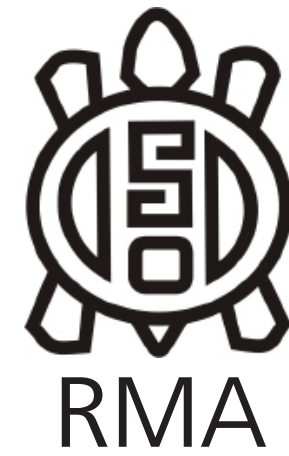

Antropología Social

\title{
Protestantismo aymara: La iglesia adventista como espacio de movilidad entre el altiplano chileno-boliviano y la ciudad en Arica-Chile
}

\author{
Aymara Protestantism: The Adventist Church as a space of mobility \\ between the Chilean-Bolivian highlands and Arica-Chile
}

Nury Concha Palacios* y Miguel Ángel Mansilla Agüero**

\begin{abstract}
*Instituto de Estudios Internacionales -INTE, Universidad Arturo Prat, Chile.
\end{abstract}
E-mail: nury.concha@gmail.com

**Instituto de Estudios Internacionales -INTE, Universidad Arturo Prat, Chile. E-mail: mansilla.miguel@gmail.com

\begin{abstract}
Resumen
El objetivo del presente artículo es describir el proceso de construcción de la comunidad evangélico-aymara, en este caso la Iglesia Adventista Aymara en la ciudad de Arica. Destacamos su presencia en los espacio andino chilenoboliviano, presente en la región desde principios del siglo XX. Resaltamos las más importantes ritualidades culticas adventistas. Luego desarrollamos los antecedentes del adventismo en Chile y Bolivia. Además, describimos nuestra temática central relacionada con la Iglesia Adventista Aymara en donde recalcamos 3 aspectos como: Incorporación de individuos desconectados de la comunidad indígena; Valoración del cuerpo estigmatizado; y Escolarizando al individuo despreciado, lo que nos ayudan a entender por qué el adventismo ha resultado significativo para el mundo aymara. Metodológicamente se trata de una investigación de Estudio de Caso, de tipo cualitativa, en donde aplicamos distintas técnicas de recolección de información.
\end{abstract}

Palabras clave: adventismo; comunidad aymara; espacio de movilidad; evangélico; indígena.

\begin{abstract}
The objective of this article is to describe the process of building the evangelical-Aymara community, in this case the Aymara Adventist Church in the city of Arica. We emphasize its presence in the Chilean-Bolivian Andean space, present in the region since the early twentieth century. We highlight the most important Adventist cult rituals. Then we develop the background of Adventism in Chile and Bolivia. In addition, we describe our central theme related to the Aymara Adventist Church where we highlight 3 aspects such as: Incorporation of individuals disconnected from the indigenous community; Stigmatized body assessment; and Schooling the despised individual, which helps us understand why Adventism has been significant for the Aymara world. Methodologically it is a case study investigation, of a qualitative type, where we apply different information collection techniques.
\end{abstract}

Keywords: Adventism; Aymara community; space for mobility; evangelical; indigenous.

El nacimiento de la comunidad étnico-adventista, Iglesia Adventista Aymara, se debe a que algunos de los fundadores de esta congregación son migrantes de la zona cordillerana chilena-boliviana, que llegaron a la ciudad de Arica desde la década de los ochenta en adelante, y que han rescatado el uso de la lengua aymara, creencias y prácticas aymaras coincidentes con las prácticas religiosas de la congregación.

La Iglesia Adventista para efectos de esta investigación se le considera como parte de la tradición evangélica, que engloba a los protestantes y (neo)pentecostales, y específicamente se les considera del lado protestante y no del pentecostal debido a que coinciden con elementos doctrinales claves como el advenimiento, la salvación por gracia, la experiencia de conversión y la preponderancia de la interpretación y aplicación de las enseñanzas bíblicas en la vida cotidiana de los creyentes. Pero el adventismo se distingue en la relevancia prestada a guardar el sábado, la significancia y relevancia en torno a la salud, el cuidado del cuerpo y el medioambiente por medio de la doctrina de la vida natural. Como también difiere del (neo)pentecostalismo en relación a las manifestaciones y 
experiencias carismáticas en cada participante.

En el ámbito de las políticas públicas e investigaciones académicas no hay distinción entre evangélicos y protestantes, concibiendo lo evangélico a todas las prácticas religiosas no católicas. Tal son los casos de distintos estudios realizados en Chile como el Censo 2012, Encuesta Bicentenario 2019, entre otros; en donde se marca las categorías de católicos, Evangélicos, Agnósticos, ateos y otros.

A partir de lo anterior, el caso de los adventistas puede identificarse como un grupo protestantes y de los menos estudiado en Chile. Encontramos diversos trabajos sobre metodistas, anglicanos, luteranos y pentecostales (Foerster, 1986; Valenzuela, 2000; Ortiz, 2009; Mansilla y Orellana, 2011; Mansilla, et.al., 2016; entre otros). Pero no encontramos trabajos sobre los adventistas como en otros lugares del continente. (Flores, 2008; Plenc, 2011, 2013; Greenleaf, 2011; Vázquez, 2009; Castañeda-Seijas, 2012).

Y desde lo mencionado, entonces, cabe preguntarse ¿Por qué es relevante estudiar los adventistas en un contexto indígena, cuando los espacios indígenas tradicionales van perdiendo relevancia frente a lo urbano? En primer lugar, porque los adventistas se encuentran en los espacios indígenas aymaras (chileno-peruano-boliviana) desde el año 1915. Incluso en el altiplano peruano, específicamente en Platería, se encuentran desde el año 1911 con un importante trabajo en el plano de la educación. Labor realizada por Zúñiga Camacho, quien fundó la Escuela Rural Indígena en la ciudad de Puno (Sthal, 1919), y para quien la educación era la única vía para la superación de la pobreza y la exclusión étnica a la que estaban sometidas las comunidades indígenas aymaras y quechuas de esa región del Perú (Vargas, 2017; Maquera, 2016; Bermejo y Maquera; 2019). En el caso de la frontera chilena, los adventistas primero se situaron en los valles de Huara y Pozo Almonte en el año 1915 y luego en el altiplano, específicamente en Camiña desde el año 1930.

En segundo lugar, los primeros investigadores sobre protestantismo y el mundo aymara redujeron los estudios al pentecostalismo bajo el englobador concepto de evangélicos (Pérez, 1975; Tudela, 1993, Van Kessel, 1993; Guerrero, 1994, entre otros.), sin distinguir las particularidades, distintivos y posibles encuentros de los adventistas con el mundo aymara, sobre todo en el plano de la educación, la salud, la alimentación, la imagen del cuerpo, la vida natural y el milenio. Esta tendencia investigativa y académica es enfatizada en la década de los ochenta, con Van Kessel (citado en Gundermann y González, 2008) quien propone una visión holocaustica del mundo andino del norte de Chile, específicamente de la cultura aymara, a raíz de los procesos de modernización llevado a cabo por el Estado chileno, y la irrupción de la doctrina pentecostal, haciéndola extensiva a todos los evangélicos, cuando la relación adventista y cultura aymara es distinta de la pentecostal.

En tercer lugar, siguiendo lo que señalan Gundermann y González (2008), para quienes la religiosidad aymara no ha sido ampliamente estudiada. Según los investigadores, los estudios clásicos se centran sólo en los espacios rurales, obviando los espacios urbanos. Esto no ha cambiado con el renacimiento de las investigaciones (Mansilla, 2014; 2016; 2017; Mansilla \& Piñones-Rivera, 2017; Mansilla, Leiva y Muñoz, 2017; Mansilla, Muñoz-Henríquez y Piñones-Rivera, 2018, entre otros), quienes han abordado este tipo de religiosidad desde distintas perspectivas como, por ejemplo, género, identidad, política, ruralurbana, etc., pero las investigaciones en relación al mundo aymara y evangélico, siguen siendo pentecoscentristas. No obstante, la gran deuda investigativa en materia del protestantismo chileno radica en el vacío de información sobre el adventismo primeramente y sobre el adventismo aymara, específicamente. Por consiguiente, en materia de protestantismo andino, y de manera específica, del adventismo aymara, la literatura existente surge desde sus propias filas congregacionales, por medio de investigaciones teológicas o revisiones históricas de la propia institución. Pero no hay estudios antropológicos.

La importancia que adquiere este artículo es, mostrar que una denominación protestante, como los adventistas, que da lugar para que personas aymaras conformen una iglesia adventista aymara provenientes del altiplano chileno y boliviano y, actualmente, dirigido por un pastor aymara, en donde se da un relativo vínculo étnico y religioso, aymara y adventista, chileno y boliviano, en un espacio fronterizo y urbano. Esto es un ejemplo que contrasta tantas investigaciones que se dieron durante la década de 1980 y 1990 en donde exponían al protestantismo como una religión que producía una desindigenizacióny des-aymaraización, incluso presentada como religiones etnocidas (Radovich, 1983; Robr 1997; Van Kessel, 1984/2005). El objetivo del presente artículo es describir el proceso de construcción de la comunidad evangélico-aymara en los espacios urbanos, en este caso la Iglesia Adventista Aymara en la ciudad de Arica

\section{Antecedentes de la investigación}

Tal como señalamos anteriormente, las investigaciones siguen siendo abordadas desde un contexto rural, desatendiendo el contexto urbano, más aún hoy cuando las encuestas (CASEN, 2015; 2017) muestran que el 75\% la población indígena del país reside en zonas con mayor urbanización, considerando que el CENSO 2017, destaca que 2.185.792 personas se declararon como indígenas, lo que corresponde al 12,8 \% de la población total de 19 millones de chilenos. Pero, en el caso aymara, el hecho que vivan mayoritariamente en espacios urbanos, no significa que los territorios tradicionales como los valles y el altiplano pierdan importancia para los aymaras. Como, por ejemplo, por su tradicional y ancestral vínculo con la 
naturaleza, este vínculo es más bien estacional, ya sea por las festividades patronales o agrícolas. Pero en general los aymaras hoy son más urbanos que rurales. Y esto es posible apreciar en las mismas encuestas, según las cuales, la población aymara alcanza un $6,6 \%$ de la población indígena nacional, y de esta, el $86 \%$ reside en la región de Arica y Parinacota, y de estos el $84 \%$ se encuentra en la ciudad de Arica.

Por otro lado, lo aymara no es un grupo cultural homogéneo como se destacaron las investigaciones de la década de los 80, sino diverso, por lo menos en relación a los énfasis y creencia religiosas. De acuerdo al único Informe de Estadística de los Pueblos Originarios (2002), el 91\% de la población aymara nacional se declaraba adscrito a alguna organización religiosa, de estos el $70 \%$ se declaraba católico, el 22\% evangélico, un 4\% se declara como mormón, Testigo de Jehová o de alguna doctrina ortodoxa, y solo un $4 \%$ se consideraba adscrito a una organización religiosa categorizada como "otra", lo que según el informe puede ser definida como practicantes de tradiciones religiosas ancestrales. $Y$ al igual que la totalidad de los informes estadísticos publicados, no se realiza distinción dentro del grupo de los evangélicos, asumiendo que entre este segmento se encuentras pentecostales, metodistas, bautistas y adventistas, entre otros. De esta manera no existe una mayor distinción dentro de estos datos. Solo siendo posible apreciar que, dentro de lo aymara, las practicas religiosa no son homogéneas y que siguen la tendencia de la población nacional en general, sin mayor distinción que 6 puntos según la Encuesta Bicentenario (2019) debido a su carácter étnico.

En consecuencia, lo aymara no puede ser entendido sólo a lo rural. Si bien la literatura existente muestra que lo étnico se relaciona a un sistema de producción agraria, y se observa a partir de la relación del individuo con la tierra y los territorios de asentamiento ancestral, también se observa en la relación que se construye y entiende desde la cosmovisión indígena. Hoy por hoy es necesario entender lo indígena a partir de los fenómenos migratorios experimentados desde a mediados del siglo XX, y que han dado lugar a una serie de movimientos y trasformaciones socioculturales posibles de entender desde la translocalidad (Carrasco y González, 2014) y la postcomunidad (Gundermann y Vergara, 2009). Entendiendo a la primera como aquellas relaciones sociales entre aymaras que siguen vigentes más allá de la localidad de origen; y a la segunda como las transformaciones sufridas en el tipo de relaciones sociales que ya no se enmarcan en la comunidad de origen rural y en las relaciones de parentesco, sino que se establecen desde las relaciones individuales, familiares y de grupos urbanos. De esta manera lo indígena se construye desde la traslocalización. Sin embargo, y a partir de lo anterior, este proceso podría observarse según la evolución generacional. Esto es, en una primera generación de indígenas en espacios urbanos, esto es aquellos grupos que emigran de los territorios ancestrales, se experimenta una translocalidad. No obstante, la generación siguiente, aquella que nace en espacios urbanos y con movimientos eventuales a territorios ancestrales, es posible interpretarlos desde la postcomunidad. $Y$ frente a una tercera o cuarta generación, ya con un mínimo contacto con lo ancestral y étnico, como producto también de los efectos de los procesos de blanquemiento (Mansilla y Piñones, 2017; González y Gavilán, 1990) étnico regional a razón de la experiencia de discriminación negativa, lo aymara altera su continuidad. Por lo tanto, amerita investigar lo aymara desde lo urbano.

Ahora bien, para el caso de los aymaras protestantes adventistas, la iglesia adventista siempre ha desarrollado una amplia cobertura educacional, salud y medioambiental. Actualmente, esto se traduce en prácticas atingentes a las problemáticas sociales que afectan de manera importante a la población y cultura aymara urbana, tales como la entrega de atención médica o familiar en sectores vulnerables, por ejemplo, como también una propuesta de vida saludable y amigable con el medio ambiente, que para el caso aymara se relaciona de manera directa con su cosmovisión y es por ello que la Iglesia Adventista, es una de las iglesias protestantes que más ha crecido en el mundo andino y eso es posible observarlo en las iglesias adventistas de la ciudad de Arica. Y esto se debe a que según Van Kessel (2004), el pensamiento andino es de tipo seminal basado en procesos biológicos en correspondencia a la fuerza vital generada por un universo divino que se relaciona con todo ser y acontecer dentro del cosmos, dando lugar a un sistema ético y religioso basado en el principio de complementariedad y reciprocidad del que forma parte todo lo existente, ya sea orgánico o no. Así se podría hablar según el mismo autor, de una cosmovisión agrocéntrica en donde se experimenta el culto a la vida desde donde se construye y vive el sentido de comunidad y que, a nuestro entender, este agrocentrismo también está presente en las creencias y prácticas adventistas y por ello se advienen con la cultura aymara, tales como la valoración de: "vida saludable", "vida natural", "alimentación vegetariana" y el "trabajo agrícola". Esto le permite ser un sistema social y religioso compatible con la identidad y cosmovisión aymara en relación a la concepción del ser humano y la familia en su rol comunitario y ecológico, pero en un espacio urbano; que han dado lugar a la conformación de una congregación adventista aymara en el espacio urbano, más otras congregaciones adventistas en el valle circundante a la ciudad, como los valles de Lluta y, muy especialmente, en Azapa.

\section{Estrategia Metodológica}

Consideramos que la forma más adecuada de lograr nuestros objetivos es utilizando una metodología 
cualitativa y específicamente la estrategia de estudios de casos. Hemos optado por este diseño porque permite realizar un examen completo y/o intenso de un fenómeno específico, en un marco geográfico y temporal determinado, de manera procesual, sistemática y profunda (Merrian, 1988). En nuestro caso es la iglesia Adventista Aymara ubicado en la ciudad de Arica.

En cuanto a las técnicas de recolección de datos. Una de las ventajas del estudio de caso, es que permite el empleo de diversas técnicas de recolección de datos y por ende permite elaborar una imagen multidimensional del problema, acorde a la complejidad de la vida social. Para cumplir de manera óptima nuestro objetivo hemos decidido utilizar 4 técnicas de recolección de información: la observación (participante y dirigida), la entrevista en profundidad, entrevista focalizada y la investigación documental.

En primer lugar, hicimos observaciones preliminares para seleccionar los casos y conocer dónde, cómo, cuándo y qué observar. Esto nos permitió conocer, por ejemplo, la cantidad de iglesias por distritos en la ciudad de Arica, los horarios de cultos, reuniones, campañas de evangelización, giras, encuentros, etc.

En el caso de las entrevistas, estas técnicas permitieron conocer, comprender, analizar y relacionar cómo los sujetos y las comunidades adventistas construyeron y construyen y les asignan sentido a las relaciones entre lo religioso y lo étnico. Estas entrevistas se realizaron con el objetivo de conocer experiencias de vida en el proceso de movilidad, estrategias de vida para enfrentar las dificultades y desafíos que les presenta el traslado, su adscripción religiosa, su experiencia de la adscripción nacional y étnica, etc. Para ello utilizamos criterios de selección basados en tradición religiosa, étnicas, nacionales, etarias, etc. El número de entrevistas que hemos realizado es de cuatro a distintos miembros de la congregación de la Iglesia Adventista.

Según lo observado, en la ciudad de Arica el mundo evangélico alcanza el $13,6 \%$ de la población comunal (Censo, 2012), pero como vimos anteriormente, para el caso aymara la religión evangélica alcanza hasta un $22 \%$. Dentro del cual es posible ubicar a la Iglesia Adventista organizada administrativamente en tres distritos con un total aproximado de tres iglesias en cada uno de ellos. En un total, el conjunto de iglesias adventistas en la ciudad lo componen quince iglesias, y una de ellas que se autodefine específicamente como aymara, esto es la Iglesia Adventista Aymara. Y es esta nuestra unidad de observación principal, de manera complementaria observaremos instancias de especial significado para la iglesia tales como bautizos, aniversarios, santa cena, entre otros., que para los adventistas siempre tienen un carácter cultico.
Durante el trabajo de campo, hemos logrado participar en distintas actividades, y hemos tenido contacto permanente con la profesora de la clase $n^{\circ} 1$ de la escuela sabática, Sandra Calle. Ella se constituye como la informante clave dentro del proceso de investigación y a través de ella se logra el nexo con los hermanos fundadores de la iglesia aymara. En el transcurso del proceso de observación, que se extiende desde el mes de agosto del año 2018 a septiembre del año 2019; se graban los sermones de los cultos sabáticos, cultos juveniles y asistimos a las reuniones del grupo de estudios; así mismo participamos de actividades especiales tales como la celebración del aniversario 126 de la escuela sabática, la santa cena, campañas evangelísticas y ceremonia bautismal.

El templo se ubica en la población Cabo Aroca (Arica), en las faldas del Cerro Chuño, el cual es reconocido como uno de los cerros sagrados para el pueblo aymara dentro de la región. Este sector poblacional se encuentra urbanizado y poblado desde fines de la década de los sesenta a través de proyectos habitacionales de autoconstrucción coordinados y subsidiados por el departamento social de la Junta de Adelanto de Arica (JAA), en ejercicio desde el año 1953 hasta el año 1974. Estos proyectos habitacionales de autoconstrucción consistían en la entrega de terrenos de aproximadamente 150 mts cuadrados, más la asesoría técnica y materiales de construcción, y en donde cada propietario en un trabajo mancomunado con sus vecinos, construían sus viviendas. Los pobladores iniciales de este sector provinieron de las oficinas salitreras que se cerraban, de la cuarta región y sobretodo, de los pueblos de la precordillera de la provincia de Parinacota.

El desarrollo de esta congregación se enmarca en un devenir de la propia Iglesia Adventista. De acuerdo a los relatos recopilados mediante la observación, la iglesia aymara surge a fines de la década de los noventa, y específicamente se identifica el año dos mil como el año de quiebre y separación. Producto de la decisión de un grupo de aproximados veinte hermanos y hermanas aymaras, que salen de la iglesia adventista de Arica oriente, congregación ubicada en el mismo sector poblacional antes mencionado; con el objetivo de formar una nueva iglesia adventista, pero con la característica especial de ser aymara, en donde primara la lengua aymara.

Este cisma no generó mayores conflictos con la institución ya que, en primera instancia, fue incentivado por el pastor Reynaldo Cid de la iglesia adventista de origen, quien les propuso el uso de la lengua aymara dentro de los cultos. No obstante, el conflicto fue experimentado a nivel congregacional en donde otros integrantes no aymaras manifestaban el disgusto e inconformismo por el uso del idioma originario dentro del desarrollo del culto.

Este período de constitución de la iglesia adventista aymara 
es interesante porque si analizamos el contexto histórico político de Chile, la década de los noventa es una época de transición en nuestro país, primeramente, por el retorno a la democracia y en segunda instancia en el surgimiento de nuevos actores políticos nacionales, entre ellos, los pueblos originarios. Este escenario se ve ejemplificado por la suscripción de nuestro país al convenio 169 de la Organización Internacional del Trabajo (OIT), además se constituye la Corporación Nacional de Desarrollo Indígena - CONADI, y, por lo tanto, los pueblos indígenas se constituyen como sujetos políticos en la realidad nacional. $Y$ en este surgimiento del pueblo aymara como un actor social específicamente, se constituyen nuevos cargos administrativos y autoridades políticas aymaras como son los Consejeros Nacionales Aymaras (CNA) y los presidentes de las Áreas de Desarrollo Indígenas (ADIs).

Por tanto, el nacimiento de la iglesia aymara adventista también tiene su relato en el contexto social y político de la sociedad chilena. Según lo informado y detallado anteriormente, esta congregación se constituye de manera independiente a fines de los años noventa, década clave para entender el Chile de hoy. En los primeros hallazgos de esta investigación, según lo informado, este grupo de miembros de la nueva iglesia aymara, inicia el éxodo tras observar en su iglesia inicial, la poca aceptación por parte de su congregación, al grupo que tenía como práctica común hablar aymara dentro de la escuela sabática.

Por último, aquí usaremos permanentemente el concepto de hermano/a por cuatro motivos: a) resaltan la fraternidad religiosa (hermanos evangélicos); b) resaltan la fraternidad étinico-comunitaria (hermanos aymaras); c) fraternidad transfronteriza (hermanos bolivianos y chilenos); d) Este trabajo será distribuido a la comunidad adventista aymara como respeto, gratitud y reconocimiento de la apertura a sus saberes personales y comunitarios, y que, en efecto, no habría ciencia sin la relación de confianza, solidaridad y reciprocidad de saberes, resaltado por la comunidad étnico- religiosa, aquí encontrada.

\section{Antecedentes del Adventismo en la frontera chilena y boliviana}

Según los antecedentes expuestos por distintos medios de la iglesia adventista y las escasas publicaciones de artículos académicos, dicha iglesia en Chile tiene una trayectoria que inicia a finales del siglo XIX en el sur de país con la llegada de una familia proveniente de Francia y que practicaba este credo. Sus prácticas religiosas, como es la experiencia generalizada de esta congregación en la introducción del credo en nuevos territorios, se enfocó a la difusión de material bíblico impreso a través de colportores. Tras quince años de trabajo misionero realizado por distintos colportores extranjeros, en 1895 se constituye la Misión Chilena de la Iglesia Adventista, en el pueblo de Huara, distrito de lquique, evento que es acompañado con el nombramiento del primer pastor chileno. Según Mansilla y Muñoz (2017, pág. 241) la iglesia adventista arribó a lquique en 1902, extendiéndose luego a las oficinas salitreras y estableciéndose en Huara. Actualmente posee pequeños templos en Matilla, Moquella, Pica, Pozo Almonte, Camiña y La Huayca. $Y$ es en la ciudad de Iquique en donde se organiza la primera congregación adventista administrada por este primer pastor chileno. E incluso en esta misma ciudad se establece la sede suramericana de la Misión de la Costa Occidental que abarca Chile, Perú, Ecuador y Bolivia.

Una vez aceptada la doctrina y congregación adventista en Chile, dos hermanos emprenden viaje desde Chile a Perú para iniciar el trabajo evangelístico en esta nueva misión. No obstante, no existe mayor información sobre el desarrollo histórico de esta congregación en la ciudad de Arica, en donde los relatos de esta congregación más cercana es lo citado por Mansilla y Muñoz (2017) y lo referente a la iglesia en Puno y Arequipa, Perú. Pero principalmente en Puno en donde además se reconoce que, por la labor de un adventista pro-indigenista, se establece la primera escuela pública para indígenas como una vía no solo de evangelización, sino que también, de reivindicación de los derechos indígenas del Perú (Sthal, 1919).

Por otro parte, para el caso boliviano, de acuerdo a lo publicado por la propia organización de la Iglesia Adventista del Séptimo Día, Bolivia fue el último país suramericano en donde ingresó esta doctrina mediante el trabajo evangelístico del colportor Juan Pereira y el primer converso boliviano en el año 1897. Según Antonio (2016), la doctrina adventista había logrado acogida entre la población aymara de la ciudad de La Paz, desde principios de siglo hasta la década de los cuarenta, tras su ingreso por la ciudad de Oruro en 1897. Al respecto Antonio menciona "Al inicio, los colportores procedían principalmente desde Chile. De este modo, ellos llegaron por la vía Valparaíso - Antofagasta - Oruro - La Paz. El tráfico de pasajeros, por esta ruta, permitió realizar una labor de colportaje permanente, circunstancial en esta ciudad" (Antonio, 2016, pág. 53).

Al respecto, Ströbel-Gregor (1989) menciona que la acogida alcanzada por los adventistas entre las comunidades aymaras en Bolivia, a partir del año 1904 aproximadamente, se debió a la asistencia sanitaria y social que desarrollaron los misioneros adventistas, lo que les permitió ser tildados como los "gringos buenos" a razón del origen norteamericano de los misioneros adventistas, y por las acciones benéficas que entregaron a las comunidades aymaras y campesinas de La Paz.

Por tanto, el adventismo inicialmente, tuvo mayores adeptos entre población caracterizada por su pobreza y estado de exclusión social, situación que puede ser comprendida sobre la ayuda social que las mujeres adventistas comienzan a llevar a los hogares como práctica evangelística adventista. Sin embargo, a partir de 
esta misma década, mediante cambios en las formas de organizar y ejecutar los congresos y por la designación de delegados en otras ciudades como Oruro, Cochabamba, Santa Cruz y Sucre, se vio como resultado, un paulatino crecimiento congregacional adventistas, siendo la primera congregación fuera de La Paz, en Cochabamba. Y es a partir de la década de los cincuenta en donde se inicia el registro de congregaciones establecidas fuera de La Paz y compuestas también por personas aymaras. Sobre el desarrollo del adventismo en Bolivia, Antonio menciona

Finalmente, el evento [el adventismo] se convirtió en un medio para integrar a los miembros de distintas ciudades, regiones, etnias, razas y clase social. Esta iglesia dejó de tener una presencia rural, regional y empezó a adquirir un matiz urbano y nacional (Antonio, 2016, pág. 23)

Pero en su análisis sobre las condiciones sociales que influyeron en el desarrollo del adventismo en Bolivia, Antonio resalta la característica mayoritaria de la pertenencia étnica aymara de los creyentes adventistas. Al respecto señala que

La identidad y la composición social adventista tuvieron un rostro y una imagen indígena, rural y altiplánica hasta fines de la década de 1940 (Antonio, 2016, Pág. 184)

Según el análisis del autor, la importante presencia de misioneros y creyentes adventistas en la iglesia boliviana afectó el desarrollo de la mismo debido a las condiciones socioeconómicas presentes en las comunidades indígenas $\mathrm{y}$ al prejuicio anti-indigenista existente en el territorio boliviano. Pero lo relevante de esta investigación se refiere al desarrollo del adventismo en la ciudad de Oruro y sus alrededores, localidades que se encuentra al límite fronterizo con Chile, y que se caracteriza por el alto flujo de personas entre estas regiones, producto de ser un territorio ancestral que cubre parte de Bolivia, Chile y Perú, con los distintos flujos económicos entre ambos países debido al desarrollo minero de Potosí y posteriormente, el desarrollo de las oficinas salitreras. Y que, en los últimos años con el desarrollo minero en la zona norte de Chile, la zona franca y el desarrollo turístico, así como la posibilidad de trabajar en los valles, ha hecho que las iglesias evangélicas entre ellas, la Iglesia Adventista, se constituyan en puentes y redes en los procesos de migración y movilidad fronteriza y transfronteriza.

\section{Iglesia Adventista Aymara de Arica}

En su fundación se identifica a un grupo de cinco personas de los cuales, actualmente, sobreviven dos mujeres y un hombre (a quienes entrevistamos), con un promedio de edad de setenta y cinco años. Según el relato de una de los fundadores, la congregación se conformó por personas oriundas de los pueblos de la cordillera de la región, e incluso su tío, cofundador de la iglesia, y su propia familia, provienen de un pueblo boliviano ubicado en el límite de la frontera entre Chile y Bolivia. Estos fundadores habrían descendido del altiplano chileno y boliviano a la ciudad de Arica en busca de mejores condiciones de vida, y al llegar a la ciudad habrían decidido constituir una congregación evangélica pero que, al encontrarse con la iglesia adventista de la ciudad, se adscribieron a esta iglesia.

Este es el caso de la hermana Delfina, una de las fundadoras y oriunda del pueblo de Caranga, en Bolivia. Según lo que ella relata, siendo niña acompañaba a su madre al templo adventista, y al casarse dejó de asistir debido a que su marido no estaba interesado en este tipo de doctrina cristiana. Sin embargo, esta situación cambió cuando Delfina fue sanada por Dios tras la visita de un misionero adventista, lo que le permitió reencontrarse con su madre, de quien se había distanciado, y con su fe por medio del bautismo. Luego, en la década de los noventas, se traslada a Chile asentando su residencia en el valle de Azapa, en donde es visitada por otro adventista quien le invita al templo adventista en un día sábado. En este encuentro, la hermana Delfina comenta que se sorprendió al saber que en Chile también estuviera la iglesia adventista y que se guardara el sábado, información que le permitió integrarse a la congregación adventista de Arica Oriente.

En el caso de otra de las fundadoras, la hermana Sandra, ella creció en el sector de Visalla, cercano al pueblo de Guallatire, en la cordillera chilena. Ella relata que fue criada por su hermano y luego en la ciudad de Arica se encuentra con su tío proveniente de Bolivia, y juntos se convierten al adventismo participando en la congregación de Arica Oriente. Así mismo, el hermano José, otro de los fundadores, relata que creció en el valle de Lluta en la ciudad de Arica, sin embargo, es cuando se traslada a la ciudad de Arica en el año 1992, que se convierte al adventismo, e inicia su participación en la misma congregación adventista de Arica Oriente. Fue así como hermanos aymaras provenientes de distintos sectores se reunieron para dar forma al Iglesia Adventista Aymara.

Actualmente, los fundadores y primeros miembros de esta congregación se agrupan en la clase $n^{\circ} 1$ de la escuela sabática, y tal como lo mencionó el pastor de esta congregación, Víctor Araos, en la escuela sabática del día 29 de septiembre del 2018, y se constató en el aniversario de la escuela sabática del día 13 de octubre del 2018, los integrantes de la clase $n^{\circ} 1$ de la escuela sabática, son un grupo de adultos mayores que conservan la lengua aymara como lengua materna, utilizada cuando se sienten en confianza, para el diálogo privado. Esta reserva en el uso de la lengua aymara es una práctica que se conserva no sólo en este grupo de estudio, sino también en distintas comunidades indígenas de la región, sobre todo los adultos mayores, como consecuencia del proceso de chilenización al cual fue sometida la región, 
en donde el hablar aymara se consideraba una ofensa a la nación y en donde muchas familias sufrieron represalias por su uso (Este relato se condice, con el rol que cumplió la escuela en la pérdida de la lengua en González, 2002; y Gundermann, 1997, 2011).

Junto con el cuidado o la reserva para hablar la lengua aymara, también se observa que, en su uso en el diálogo entre las personas aymaras, las conversaciones se realizan en un volumen de voz muy bajo, casi indescifrable para el oído no familiarizado con el idioma y la dinámica de comunicación. Esta forma de interacción silenciosa se transforma en una barrera entre quienes son de su confianza o no.

Pero ¿cómo surge esta práctica de hablar aymara en los cultos? Según lo relatado por algunos de sus fundadores, en la iglesia adventista de Arica Oriente, el pastor que lideraba la iglesia se acercó a los fundadores de la iglesia aymara, y les entregó una biblia escrita en aymara, instándolos a que usar esta biblia y a que usar este idioma dentro de la clase de la escuela sabática exclusiva para los aymara hablantes. Con esta iniciativa entonces, en esta clase de la escuela sabática, empiezan a agruparse integrantes de esta congregación descendientes de los pueblos aymaras de Chile y de la macrorregión andina, con un manejo amplio o básico del idioma aymara. Este dominio del idioma les instó a perfeccionarse en su uso y lectura del mismo, y en cierta medida, se volvió una vía para el rescate de sus tradiciones andinas. Con respecto a este proceso de conformación del grupo de adventistas aymaras, se nos informa lo siguiente

"...mira, en realidad estas cosas son, son así..., nosotros salimos el pequeño grupo, de la iglesia oriente, primero congregamos en iglesia oriente, en iglesia oriente congregamos, éramos una clase como las que estamos allá, una clase que tratamos de hablar aymara, yo tampoco perfecta era, sino que a mi me regalaron una biblia aymara pastor Cid, el pastor Reinaldo Cid, él me regaló una biblia aymara. Yo después compré otra biblia aymara, tengo dos biblias, ahí tengo biblia aymara. Entonces el hermano me dijo "aquí está la biblia aymara, te regalo, ahora va ser tuyo". Yo empecé a leer, a leer, leer, leer, empecé a leer. Ahí más capacité hablar aymara. ¿Ya? Entonces eso nos apoyó. Y hemos podido aprender. Te acuerdas [le dice a otra hermana que nos acompañaba en la entrevista], yo tenía un himnario de aymara y eso no era adventista, yo no sé de donde compré, no sé, era aymara, el himnario aymara, entonces yo fotocopie a toditos le di, así estamos un grupito, en la casa del hermano Evaristo. Después ahi empezamos cantar, cantar aymara. A ellos les gustaban porque ellos eran aymara, de Camiña son ellos. Hermana Basilia también, pero ella más para arriba de Camiña. Pero las otras somos de acá o venimos de familias de Bolivia, ya, todos los hermanos hablamos aymara, nos juntamos. $Y$ también venía la mamá de la agüelita, la Crispín Chura, su mamá, su esposo, el hermano Crispín, ellos también venían, por lo que cantaban en aymara, decían, "cantamos, cantamos" decían. ¿Ya?, ¿después ya éramos hartos en el grupo, salimos ya, apartándose, salimos de la iglesia oriente, un grupito, qué nombre? Como hablábamos aymara no más, entonces le vamos a poner Iglesia Aymara" (Sandra).

Según lo expuesto en estos relatos, es posible apreciar la importancia que alcanzó el hecho de recibir una biblia en aymara. Este tipo de ediciones de la biblia constituyen el resultado de un largo proceso de traducción en el reconocimiento de la cultura aymara. Ejemplo de esto es lo señalado por la Sociedades Bíblicas Unidas, según la cual fue Diego Thomson, quien junto al ex-sacerdote católico Vicente Pazos Kanki (exiliado en Londres en 1817), intentaron traducir el Nuevo Testamento al aymara. La traducción concluyó a fines de 1826. Pero el único texto que lograron publicar fue el Evangelio de Lucas en 1828, y fue el primer evangelio traducido a un idioma vernáculo de América del Sur. No obstante, la traducción del Nuevo Testamento fue publicado por primera vez en 1954 y de la Biblia fue publicada por primera vez en 1986. La traducción de la Biblia en idiomas indígenas, se constituyó en uno de los temas más controversiales en la década de 1980, involucrando a antropólogos, intelectuales de izquierda y la Iglesia Católica, quienes veían en esta institución la ideología yanqui y la protestantización de los indígenas.

De este modo la Biblia en la propia lengua, en este caso en aymara, para las personas entrevistadas resultó ser un revival de su lengua y a través de ella, de sus costumbres ancestrales. Las personas entrevistadas resaltaron sobre lo que significó emocional y afectivamente leer la Biblia y cómo a medida que leían las palabras en aymaras significó recordar sus raíces, su lengua materna, la hablada por sus padres y ancestros, y que les permitía autodefinirse como aymaras, señalando su presencia como etnia dentro de la congregación que, según su percepción, no les reconocía. Por consiguiente, la apropiación que se alcanzó no solo sobre el objeto sagrado recibido, sino que se aprecia el realce alcanzado de la identificación de una identidad diferente a la occidental, un reconocimiento a la identidad aymara dentro de la congregación religiosa reconocida 
como un grupo específico de la escuela sabática. Si bien, se observa la existencia hasta una tercera generación descendiente de la primera congregación adventista aymara, que no presenta un mayor uso de la lengua aymara en sus cultos, sí es posible observar algunas manifestaciones de identidad aymara. Señal de esto fue lo observado en el culto sabático del 29 de septiembre de 2018. Durante el desarrollo del culto se observa lo siguiente

En su mayoría, los asistentes presentan fenotipos indígenas, vistiendo ropa formal. Las hermanas ancianas, sobre todo, mantienen cierta tradición en la vestimenta tradicional andina nacional, esto es faldas rectas, largas, suéteres de lana y sombrero de paja. Visten también, zapatos bajos generalmente negros. La mayoría usa el pelo largo, ya sea suelto, que cuelgan sobre sus espaldas o semi tomado. Las hermanas más jóvenes presentan vestimenta y adornos occidentales, y llevan el pelo teñido, suelto y corto sobre los hombros. En el caso de los hermanos, se aprecia que en su mayoría visten ropa semi-formal, reemplazando la chaqueta de vestir por la chaqueta cortaviento. Los colores que predominan son el negro, gris, azul y verde oscuro. En el caso de los hermanos jóvenes se observa que mayoritariamente usan traje de vestir negro y camisas blancas o celestes. Las hermanas jóvenes están vestidas en su mayoría con distintos tipos de vestidos o faldas, de distintos largos y distintos colores. Usan zapatos de colores con tacones altos. Se observa que tanto el largo, color y peinados son diversos.

Por tanto, fuera de los rasgos fenotípicos asociados a lo andino, en este caso aymara, no se observan mayores distinciones de pertenencia formal a la cultura aymara (como sí lo es en iglesias aymaras bolivianas) en las generaciones más jóvenes, es más, los atuendos asociados a esta etnia se presentan en el grupo de fundadores de esta congregación. No obstante, es posible observar que la segunda generación adulta de la congregación aún manifiesta mayor identificación con distintas manifestaciones y prácticas aymaras. Ejemplo de esto se puede apreciar durante la exposición del sermón por medio del pastor, el cual también se identifica como aymara, se describe los siguiente

Al iniciar su intervención el pastor, este separa tras el púlpito, a diferencia del hermano coordinador que lo realiza desde un costado del altillo, al lado del púlpito. Su intervención se inicia saludando a la congregación en aymara, diciendo kamisaraki, a lo que la congregación responde waliki. Luego, y en tono ameno agrega Hello, who are you, sin lograr respuesta, pero sí pequeñas carcajadas y sonrisas. Luego el pastor menciona que en medio de la congregación se encontraba una investigadora que se está dedicando a realizar un estudio sobre los hermanos aymaras, lo que provoca una gran aprobación y entusiasmo en la congregación. El pastor incluso se identifica como aymara lo que provoca una reacción positiva por parte de la congregación. En esta instancia el pastor presenta la investigadora a la congregación y esta le saluda y le pregunta si sabe hablar aymara. Ella les respondo que sabía algunas palabras, y frente a esto una hermana que se encontraba más adelante, la invita a aprender la lengua y que ellos le pueden enseñar, por lo que se les agradece y les manifiesta el interés por aprenderlo.

De esta manera se observa como elemento identitario de la cultura aymara, el uso de la lengua aymara. Sin embargo, esta distinción antes del éxodo, dio lugar a la identificación de un otro distinto dentro de la congregación, dando lugar a la segregación de esta clase dentro del culto. $Y$ respecto a este proceso, otra de sus fundadoras manifiesta lo siguiente

"...así era, a un lado ahí nosotros, puro aymarita, ahí estamos sentao, nunca, nunca hacía cuenta nada, y se hacía escuela sabática a todos ellos, eh, nosotros así oyente no ma' éramos, la hermana Leo "yo puedo facilitar casa, por qué nos separamos?, ¿por qué nos apartamos? Puro aymara". Ahí nos apartamos, ahímás bien, escuela sabática o culto divino, todo allá aprenden, salir. Allá no pu, como oyente no ma', estábamos en un ladito y todos ellos en otro lado. Ahí salimos, salimos, sí. Nosotros nos dábamos cuenta, así estábamos. Ahí salimos." (Delfina)

De esta forma se aprecia que la intención que permitió el éxodo de este grupo de creyente se debe al rechazo y falta de oportunidades de ejercer alguna labor o rol importante dentro de la congregación. Y con el surgimiento de la nueva congregación

"...algunos, a algunos. Algunas como que no tanto. Pero yo siempre había pedido en el programa del JA, un parrafito, póngame. Yo le voy a hablar en aymará para que aprendan los jóvenes, pero no me le han puesto... No se atreven a hablar. Por ejemplo, el hermano sabe aymara, puede hablar aymara. El hermano sabe aymara. Pero no se atreve a hablar". (Sandra)

"Siempre yo escucho "quiero escuchar una palabra aymara" "para aprender vengo" dicen. De puro castellano acá 
también. ¿Cómo dicen acá Iglesia aymara? Así dicen, que quieren aprender también, pero nadie les habla aymara (...) "Mi papá, mi mamá era aymara legítimo, mi abuelo también. Yo también era así, ni una palabra castellano, no conocía castellano yo. Yo soy de Bolivia, de Bolivia me vengo aquí y aquí he aprendio hablar castellano, pero, me gusta hablar aymará. No tengo vergüenza hablar aymará. Mis hijos también aymara, hablan todo. La única es mi hija sabe todo, entiende todo, pero no sabe hablar. Kamisaraki, eso sabe noma mi hija". (Delfina)

"...es que una cosa, esta cosa, pienso que cuando empiece hablar aymara, hay que hablar aymara hasta que hable bien. Porque si vamos mezclando, mezclando nunca va a ser correcto. Yo nunca me voy a olvidar de niño chico, de ocho años salí pa fuera y nunca me voy a olvidar, yo voy a aprender castellano legal. Lo que pasa que ese aymara que yo sabía nunca me voy a olvidar hasta hoy. Nunca olvidé, muchos han olvidado. Hablaran, yo no sé." (José)

Según otra informante, con el pasar de tiempo y la presencia de nuevas generaciones y asistentes no aymaras, esta práctica se fue dejando para ser aplicada sólo en la clase $n^{\circ} 1$ de la escuela sabática.. Por tanto, la clase $n^{\circ} 1$ de la escuela sabática agrupa a los fundadores sobrevivientes y es liderada por la sobrina de unos de los cofundadores. En total se agrupan alrededor de ocho personas, en su mayoría adultos mayores.

Se observa que en el grupo de la Iglesia Adventista aymara que dentro de la primera generación conformó esta congregación, también es la generación que emigra desde el altiplano hasta la ciudad de Arica ubicada en el piso costero de la región y como tal, ellos han perseverado en algunas tradiciones aymaras como y específicamente lo es la vestimenta y el idioma teniendo en sus registros cercano, en la idea de la tradición en comunidad de los pueblos del interior.

El desplazamiento de los aymaras desde el altiplano o desde los valles hacia las ciudades, si bien no es un fenómeno nuevo, se intensifica a partir de la década de 1980. Durante este proceso migratorio, sostiene que los evangélicos cumplieron una función de comunidad-puente, facilitando el arraigo en la urbe. (Mansilla y Muñoz, 2017, pág.242)

Sin duda estos relatos son claves para iniciar el proceso de constitución de la historia de esta congregación como también, para la comprensión de su propia identidad.
A partir de esto se observa primero que la Iglesia Adventista aymara obtuvo cierto realce debido al trabajo evangélico misionero por medio del Ministerio Musical Nuevo Amanecer constituyéndose una estrategia para la incorporación de nuevos creyentes. Sin embargo, las generaciones más jóvenes presentaron un escaso interés en la adopción de aprendizaje de la lengua aymara debido a un distanciamiento de las tradiciones andinas y residencia en el sector urbano de la región, dentro de los patrones de la cultura occidental.

En el video musical" "Aunque en esta vida (en aymara)" se muestra este encuentro entre el altiplano y lo urbano, lo aymara y lo adventista, en este puente agrocultural, como es el Valle de Azapa, en donde se encuentran a lo menos 6 iglesias adventista y lo paradójico, es que todas estas iglesias están compuestas mayoritariamente de aymaras, pero no hay interés por resaltar o rescatar la cultura andina, como lo es en la pequeña comunidad adventista aymara.

Tal como se describió anteriormente, uno de los ejes fundamentales del adventismo es la evangelización. ¿Por qué es importante el proceso de evangelización para una persona aymara? Porque, a diferencia del mundo pentecostal, en donde cualquier nuevo creyente puede predicar y dar sus testimonios en la calle; en el caso adventistas pasa por rigurosos procesos de evangelización y discipulado, que la evangelización es presentada como privilegio y prestigio comunitario, por un lado, y el sentirse parte de algo relevante para una comunidad, viene a ser muy relevante para estas personas que siempre han sido excluida de lo relevante comunitaria y socialmente, por otro lado. Para el caso de la congregación, se aprecia una distinción en su ejercicio en un período inicial de la historia de la congregación en estudio. Y este eje doctrinal se desarrolló por medio del discipulado y el ministerio de alabanza. $Y$ de esto una de las fundadoras de la congregación afirma

"...en esos años éramos muy misioneros. Bautizábamos a matrimonios completos, la gente, ¿ya? de Arica, ya, y formamos un conjunto instrumental, ya? Entonces todo eso, todo este trabajo como que ya...más llamativo, ya. Entonces teníamos más amoroso con las personas, ya, cariñosos, qué se yo. Entonces, como el pastor siempre estaba con nosotros, muy activo, muy motivadora, decían, eh, el conjunto aymara. Pero el conjunto no era aymara, era conjunto nuevo amanecer...cantábamos aymara, cantábamos en castellano...las niñas cantaban aymara. Entonces, eso, más llamativo, porque la música siempre ha

\footnotetext{
${ }^{1} \mathrm{https}: / /$ www.youtube.com/watch?v=1RWjl8c-xtk
} 
sido ha atraído a las personas. Entonces ya salimos visitas, ya teníamos permiso para salir, donde no viajamos, ya. Ahíya, viajando rescatamos las almas perdidos también, eso también. Viajamos mucho. Putre no hay nada que decir, montón de veces hemos ido, a Tacna hemos ido, a Bolivia hemos ido. Iquique hemos ido, Camiña hemos ido. A donde no hemos ido. Entonces ya". (Sandra)

Fuera de esta experiencia del grupo musical dentro de los cultos observados y conversaciones realizadas con los integrantes de la congregación en estudio, no se percibe otras actividades de evangelización específica como congregación aymara salvo la anteriormente mencionada. Como congregación adventista sí da cuenta de las actividades que como denominación realizan y que son programadas a nivel nacional, esto es el trabajo del grupo juvenil o el grupo conquistadores conformados por niños y niñas que más que realizar actividades directamente relacionadas al discipulado de los creyentes, se enfoca en la realizar el trabajo como colportaje. En relación a esto, cabe mencionar lo observado el sábado 15 de septiembre, en el culto juvenil cuyo sermón estuvo a cargo de una de las fundadoras de la congregación aymara, la hermana Sandra Calle. El tema tratado se enfocó en la labor del colportor $^{2}$ en donde se destacaba la importancia de dar a conocer la doctrina de la iglesia, el mensaje evangelístico y la literatura existente.

Por medio de este mensaje se destacó la importancia de ser perseverante y de la confianza en Dios para realizar esta actividad. Así mismo, la hermana a cargo del tema invitó al grupo de jóvenes presentes a inscribirse en el próximo proceso de postulación para ejercer como colportor de la iglesia. Por tanto, en el período observado, este sermón ha sido el único dedicado directamente a este proceso de evangelización.

Otro punto importante a destacar se refiere a lo que también manifiesta Vázquez (2008) como relevante para la doctrina adventista, como para muchas doctrinas protestantes, el cuerpo es símbolo del lugar de habitación divina, de un lugar de recepción y receptáculo de lo divino, para lo cual se requiere de su purificación y cuidado. También es visto como aquel testigo que experimentará el advenimiento de Cristo a la tierra. Por tanto, y en respaldo a leyes judaicas adscritas por medio del canon bíblico, para la doctrina adventista el cuidado del cuerpo es fundamental para su purificación, lo que se traduce en prácticas alimenticia saludables, en donde se promueve la abstención de alimentos derivados de animales y prácticas deportivas como vías para la permanencia del cuerpo en un estado favorable para el trabajo evangelístico, también

\footnotetext{
${ }^{2}$ El colportor se refiere al que distribuye literatura adventista como estrategia de evangelización.
}

como eje central del adventismo. $Y$ esto podemos observarlo en el sermón presentado en el Culto Sabático Sagrado del sábado 08 de diciembre de 2018, que dice

Dios quiere que alcancemos el ideal de perfección, hecho posible para nosotros por el don de Cristo, nos invita a escoger el lado de la justicia a ponerla en relación con los agentes celestiales; a adoptar principios que restauraran en nosotros la imagen divina. En su palabra escrita y en el gran libro de la naturaleza es revelado los principios de la vida. Es nuestra tarea conocer estos principios y por medio de la obediencia cooperar con Dios en restaurar la salud del cuerpo tanto como la del alma. En el ministerio de la curación página sesenta y siete, dice lo leído.

Y desde la cosmovisión andina estas prácticas religiosas se vinculan con el cosmos aymara, y como dijimos anteriormente, dentro de este universo espiritual, cada ser orgánico o no, es un ser vivo y complemento del otro. Y entre los seres se encuentra la tierra "pachamama", esto es la proveedora de toda vida, la cual favorece a sus hijos con el alimento que los nutre y la medicina que se encuentra en la naturaleza, para que se preserve al ser humano en un estado que no afecte la vida de la comunidad (Van Kessel, 2004 y otros).

Por tanto, ambas doctrinas convergen y se hacen compatibles en la resignificación de las prácticas saludables y del cuerpo, entre las comunidades indígenas y las doctrinas adventistas (Carrasco y Gavilán, 2009). Sin embargo, en el caso de la congregación adventista aymara, es posible observar solo el discurso doctrinal adventista dentro de sus prácticas de cuidados, pero no se oye del yatiri, qulliri ni de la usulliri, ni del uso de la unidad de cuidados intercultural del servicio público, y tal como dice una hermana adventista no aymara de la congregación en un culto de oración, "lo aymara de la congregación está solo en el aymara (lengua), porque antes traían comida aymara para compartir o enseñarla, pero ahora nada".

\section{Conclusiones, Entre la simpatía y apatía comunitaria étnico-religiosa}

Lo que hemos observado en la Iglesia Adventista Aymara de la ciudad de Arica es la voluntad, por parte de la Iglesia Adventista, de autorizar para que personas aymaras, especialmente adultos mayores que migran a los espacios urbanos y que manifiestan nostalgia por los espacios y tiempos andinos, sobre todo el uso de la lengua. Para los adultos mayores, al descubrir una Biblia en lengua aymara, produjo entre ellos una revitalización de la lengua, pero también de la comunidad andina, al buscar a otros y juntarse y vivir en comunidad en los espacios urbanos. De ese modo, aprovechan de pasar la mayor parte del tiempo juntos, en cada espacio que la iglesia les permita. 
Sin embargo, pese a que la Iglesia Adventista tiene a lo menos 6 templos en los Valles de LLuta y Azapa y que todos sus congregados son aymaras, fundamentalmente de origen boliviano, no muestran interés en congregarse en la Iglesia Adventista Aymara de la ciudad de Arica, sino quedarse en su congregación. Esto tiene dos interpretaciones: a) Los evangélicos, a diferencia de los católicos, por ejemplo, construyen y mantienen vínculos comunitarios con su congregación. Es decir, mantienen lealtades espaciales y comunitarias, y no necesariamente denominacionales, aunque, el lugar donde se congreguen, se encuentren lejos de sus espacios barriales. De hecho, mucho de los aymaras que se congregan en los Valles, vine en la ciudad de Arica b) Que los aymaras se congregan en familia en sus iglesias y no asistir a otras, de manera individual; más aún cuando se trata de niños y adultos mayores, son "llevados" a la iglesia, por la familia, generalmente mujer adulta.

Pero, lo más importante, las nuevas generaciones no muestran mayor interés por ser parte de una comunidad aymara que lleve como tal un nombre, sino porque de igual modo, continúan siendo aymaras y sisntiéndose aymaras, y no como, esperamos los antropólogos, la revitalización de la comunidad étnica en la ciudad, en donde las personas hablen aymaras; hagan carnavales, se "vistan" como aymaras, etc., porque ello se trata de una "folclorización" de lo aymara. Más bien, los aymaras viven y trabajan en los valles de Lluta y Azapa, porque los valles se han constituidos en puentes entre el altiplano y la costa; entre lo rural y lo urbano; entre el campo y la ciudad. De este modo, los aymaras se insertan en la ciudad vinculados a su pasado agrario, trabajando en los valles, especialmente los aymaras bolivianos, o en negocios de verdulería, en el caso de los aymaras chilenos.

De este modo, la Iglesia Adventista, se constituye en un discurso religioso que rememora y revaloriza el sentido comunitario, en cuanto resalta la alimentación vegetariana, la vida del campo, la comida natural por sobre la artificial. De igual modo, se resalta el vínculo trasnacional y transfronterizo de la comunidad adventista, por ello los padres se esfuerzan por enviar sus hijos a universidades de ciudades de países vecinos como: Cochabamba (Bolivia), Tacna y Lima (Perú), La Plata (Argentina) o Talca (Chile).

En consecuencia, no se observa, por lo pronto, una revitalización de la comunidad Adventista-Aymara, porque de seguro, la comunidad continuará más como forma de comunidad aymara que con personas aymaras interesadas en revitalziar un imaginario comunitario, que las nuevas generaciones, consideran que esa parte de los abuelos, pero no de ellos. Estos jóvenes, siguen interesados en ser aymara; valoran lo aymara y admiran la cultura aymara, sobre todo el respeto por la naturaleza, pero no está interesado, por ejemplo en aprender la lengua aymara o revitalizar las ritualidades consideradas aymaras en la ciudad de Arica.

\section{Agradecimientos}

Este artículo es resultado del proyecto FONDECYT Regular núm. 1180924, "La fe mueve fronteras".

\section{Bibliografía}

Antonio, R. 2016. Factores externos e internos que intervinieron en la extensión del adventismo desde La Paz hacia ocho ciudades de Bolivia en el periodo 1946-1976. Tesis (Doctorado), Universidad Peruana Unión. Unidad de Posgrado de Teología. Escuela de Posgrado, Lima.

Berger, P. y Luckmann, T. (2015). La construcción social de la realidad. 1era Ed. 24va Reimpresión. Buenos Aires: Amorrortu.

Bermejo, S. y Maquera, Y. (2019) Interpretación de la escuela rural andina en comunidades aimaras de PunoPerú. Revista Electrónica Educare (Educare Electronic Journal) EISSN: 1409-4258 Vol. 23(2) mayo-agosto, 1-15.

Castañeda-Seijas, M. (2012) Experiencia de ser otro: la conversión de las identidades en la Iglesia adventista. Revista LiminaR. Estudios Sociales y Humanísticos, año 10, vol. X, núm. 2, julio-diciembre de 2012, San Cristóbal de Las Casas, Chiapas, México

Carrasco, A., y Gavilán, V. (2009). Representaciones del cuerpo, sexo y género entre los aymara del norte de Chile. Chungará (Arica), 41(1), 83-100. https://dx.doi. org/10.4067/S0717-73562009000100006

Carrasco, A. y González H. (2014). Movilidad poblacional y procesos de articulación rural-urbano entre los aymara del norte de Chile. Si Somos Americanos. Revista de Estudios Transfronterizos. Volumen XIV / Nº 2 / julio-diciembre 2014 / pp. 217-231.

Corcuff, P. (2014). Las nuevas sociologías. Principales corrientes y debates, 1980-2010. 1era edición. Buenos Aires: Siglo Veintiuno Editores.

Denzin, N., y Lincoln, Y. (2013). Manual de investigación cualitativa. Vol. III. 1 ra edición, Barcelona. Editorial Gedisa, S.A.

Flores, F. (2008) Los Adventistas del Séptimo Día en la Argentina y su "proyecto de colonización". Aportes desde un análisis histórico Sociedad y Religión: Sociología, Antropología e Historia de la Religión en el Cono Sur, vol. XX, núm. 30-31, pp. 91-106. Centro de Estudios e Investigaciones Laborales Buenos Aires, Argentina

Foerster, R. (1986). La misión anglicana, primera iglesia protestante entre los mapuches. Nütram 3: 14-28.

González, H. y Gavilán, V. (1990). Cultura e Identidad étnica entre los aymaras chilenos. Revista Chungara, N²4/25, enero-diciembre, Universidad de Tarapacá, Arica. 
Greenleaf, F. (2011) Tierra de esperanza: El crecimiento de la Iglesia Adventista Sudamericana. Buenos Aires: Asociación Casa Editora Sudamericana,

Gundermann, H., González, H., \& Vergara, J. (2007). Vigencia y desplazamiento de la lengua aymara en Chile. Estudios filológicos, (42), 123-140. https://dx.doi.org/10.4067/S0071-17132007000100008

Gundermann, H. \& González, H. (2009). Sociedades indígenas y conocimiento antropológico: aymaras y atacameños de los siglos XIX Y XX. Chungará (Arica), 41(1), 113-164. https://dx.doi.org/10.4067/S071773562009000100008

Gundermann, H. \& Vergara, J. (2009). Comunidad, organización y complejidad social andinas en el norte de Chile. Estudios atacameños, (38), 107-126. https://dx.doi. org/10.4067/S0718-10432009000200008

Instituto Nacional de Estadística (2002). Estadísticas Sociales de los pueblos indígenas en Chile Censo 2002. Programa Orígenes, Gobierno de Chile. Santiago de Chile.

Instituto Nacional de Estadística, (2012). Censo 2012, Resultados XVIII, Censo de Población. Gobierno de Chile. Santiago de Chile.

Instituto de Sociología (2019). Encuesta Nacional Bicentenario. Universidad Católica de Chile. Santiago de Chile.

Maquera, j. (2016) Operación Andes libres: construyendo la "Utopía". Ñaña, Lima, Perú: Ediciones Universidad Peruana Unión, 2014. Pp. 327.

Mansilla, M., Muñoz, W. \& Piñones-Rivera, C. (2016). El post pentecostalismo. La concepción de los migrantes peruanos y bolivianos evangélicos (quechuas y aymaras) sobre el pentecostalismo chileno. Diálogo andino, (51), 81-91.

Mansilla, M. \& Muñoz, W. (2017). La dramatización de la cultura: los procesos de conversión evangélica aymara (Chile). Chungará (Arica), 49(2), 241-250. Epub 26 de abril de 2017. https://dx.doi.org/10.4067/S0717-73562017005000014

Mansilla, M. \& Muñoz, W. (2017). ¿Evangélicos o aymaras?: dinámicas de las representaciones culturales de los evangélicos aymaras (Chile). Estudios atacameños, (54), 239-258.

Mansilla, M. A. \& Piñones-Rivera, C. (2017). Lo moreno es bello. Componentes identitario de las mujeres jóvenes evangélicas aymaras. Revista Latinoamericana de Ciencias Sociales, Niñez y Juventud, 15 (2), pp. 1005-1019.

Merriam, S.B. (1998). Qualitative research and case study applications in education. San Francisco: Jossey-Bass

Ministerio de Desarrollo Social (2015). Encuesta de Caracterización Socioeconómica Nacional, Pueblos Indígenas, síntesis de resultados. Subsecretaría de
Evaluación Social, Gobierno de Chile. Santiago de Chile.

Ministerio de Desarrollo Social (2017). Encuesta de Caracterización Socioeconómica Nacional, Pueblos Indígenas, síntesis de resultados. Subsecretaría de Evaluación Social, Gobierno de Chile. Santiago de Chile.

Muñoz, W. \& Mansilla, M. (2015). Conflacionismo epistemológico: Los estudios sobre el pentecostalismo aymara en Chile (1975-1998). Cinta de moebio, (52), 1-16. https://dx.doi.org/10.4067/S0717-554X2015000100001

Ortiz, J. (2009). Historia de los evangélicos en Chile 1810-1891: de disidentes a canutos. Liberales, radicales, masones y artesanos. Concepción: Centro Evangélico de Estudios Pentecostales.

Plenc, D. (2013). Misioneros en Sudamérica: Pioneros del adventismo en Latinoamérica - 2a ed. - Florida: Asociación Casa Editora Sudamericana.

Radovich, J. (1983), El pentecostalismo entre los mapuches del Neuquén, en: Relaciones de la Sociedad Argentina de Antropología. Tomo XV: 121-131, Buenos Aires.

Robr, E. (1997). La destrucción de los símbolos culturales indígenas. sectas fundamentalistas, sincretismo e identidad indígena en el Ecuador. Editorial Abya- Yala. Quito. Ecuador.

Ruelas, D. (2017). La Escuela Rural de Utawilaya y los adventistas en el Altiplano Puneño 1898 - 1920: Precursora de la educación rural indígena peruana y Latinoamericana. Revista Historia de la Educación Latinoamericana. 19. 10.19053/01227238.5923.

Schwarz, R. y Greenleaf, F. (2012). Historia de la Iglesia Adventista del Séptimo Día. Portadores de luz Dirigido por Aldo D. Orrego. - $1^{\text {a }}$ ed., $2^{a}$ reimp. - Florida: Asociación Casa Editora Sudamericana.

Tudela, P. (1993). Cambios religiosos y revitalización de la comunidad entre los aymaras de Arica 1960- 1990. Nütram 33: 15-48.

Valenzuela, R. (2000). Historia de la Iglesia Metodista de Chile, 1878-1903. Santiago: s/ed.

Van Kessel, J. (2004). Individuo y religión en los Andes. Cuadernos de Investigación en Cultura y Tecnología Andina, $\mathrm{N}^{\circ}$ 16. IECTA - Iquique.

Van Kessel, J. 2005 [1980]. Holocausto al progreso. Los aymaras de Tarapacá. Cedla, Amsterdam.

Vázquez, G. (2009). Eva y las manzanas: Las mujeres adventistas y la alimentación del Templo de Dios. Relaciones. Estudios de historia y sociedad, 30(117), 129-158. Recuperado en 01 de septiembre de 2019, de http://www. scielo.org.mx/scielo.php?script=sci_arttext\&pid=S018539292009000100005\&lng=es\&tlng=es.

Sthal, F. (1920). Land of the Incas. California: Pacific Press. 